\title{
Levantamento de Plantas Daninhas Aquáticas no Reservatório de Alagados, Ponta Grossa-PR
}

\author{
Assessment of Aquatic Plants from Alagados Dam, Ponta Grossa-PR \\ ROCHA, D.C. ${ }^{2}$ e MARTINS, D. ${ }^{3}$
}

\begin{abstract}
RESUMO - O monitoramento de macrófitas da represa Alagados - um reservatório artificial de água que abastece parcialmente a população do município de Ponta Grossa-PR - se faz necessário, uma vez que resíduos urbanos, bem como dejetos de áreas rurais, são descartados direta ou indiretamente nesse ambiente. Os objetivos deste trabalho foram realizar o inventário de plantas aquáticas coletadas entre agosto de 2007 e julho de 2008 no entorno do lago, como medida de monitoramento da área; indicar a frequência das espécies e apresentar um diagnóstico sobre o crescimento populacional destas; e identificar áreas onde a colonização por macrófitas é intensa, podendo tornar-se problema ambiental. Para realizar esse inventário, foram efetuadas 10 coletas em 48 pontos de amostragem ao longo das margens do lago da represa. Exsicatas foram depositadas no Herbário da Universidade Estadual de Ponta Grossa (HUPG). Foram amostradas 54 espécies, distribuídas em 16 famílias de angiospermas, 8 monocotiledôneas e 8 dicotiledôneas, e outras duas famílias de pteridófitas.
\end{abstract}

Palavras-chave: macrófitas, planta anfíbia, planta emergente, planta aquática flutuante.

\begin{abstract}
A check-list of the macrophytes in the Alagados artificial dam, which supplies part of the population of Ponta Grossa-PR, is necessary, since urban and rural waste is dropped directly or indirectly into this environment. The objectives of this work were to make an inventory of the aquatic plants collected between August 2007 and July 2008 in the lake surroundings to monitor the area; to indicate species frequency, to present a diagnosis on species population growth; and to identify areas where colonization by macrophytes is intense and could become an environmental problem. To carry out this inventory, 10 collections were conducted in 48 sampling points along the margins of the dam's lake. Exsiccates were deposited in the Herbarium of the Universidade Estadual de Ponta Grossa (HUPG). A total of 54 species were sampled, distributed in 16 families of flowering plants, 8 monocotyledons and 8 dycotyledons, and two other families of ferns.
\end{abstract}

Keywords: macrophytes, amphibium plant, emergent plant, floating aquatic plant.

\section{INTRODUÇÃO}

A presença de plantas em ambientes aquáticos continentais é fundamental para o equilibrio tanto de ecossistemas naturais, como lagos, rios e riachos, quanto dos artificiais, como reservatórios de hidrelétricas, represas e açudes para abastecimento de água. Entretanto, tem sido cada vez mais necessário o monitoramento das espécies que ocorrem nesses ambientes, uma vez que estes sofrem constantes pressões antrópicas e se alteram.

A represa em estudo está localizada no segundo planalto paranaense, a $20 \mathrm{~km}$ do município de Ponta Grossa, numa região denominada Campos Gerais, cuja formação geológica, clima, temperatura, altitude, relevo, vegetação e fauna têm merecido estudos mais aprofundados nos últimos anos (Melo et al., 2007).

1 Recebido para publicação em 5.2.2011 e na forma revisada em 6.5.2011.

2 Professor Associado, Dep. de Biologia Geral, Universidade Estadual de Ponta Grossa - UEPG, 84030-900 Ponta Grossa-PR, $<$ dalva_rocha@uol.com.br>; ${ }^{3}$ Professor Livre Docente, Dep. de Produção Vegetal, Faculdade de Ciências Agronômicas, Universidade Estadual Paulista "Júlio de Mesquita Filho" - FCA-UNESP, Caixa Postal 237, 18603-970 Botucatu-SP, <dmartins@fca.unesp.br>. 
A proliferação desequilibrada de determinadas plantas aquáticas em reservatórios de hidrelétricas causa graves prejuízos ambientais e econômicos para a sociedade, entre os quais problemas como competição e substituição de espécies nativas, geração de energia, navegação, pesca, prática de esportes náuticos, proliferação de insetos e doenças (Carvalho et al., 2003; Martins et al., 2008, 2009, 2011).

Segundo Scremim-Dias (2000), as diferentes formas de vida das plantas aquáticas refletem a zonação ecológica das espécies, que apresentam respostas adaptativas às alterações do nível da água em função da sua capacidade de resistir à submersão ou ao dessecamento. Seis diferentes formas de vida foram propostas por Irgang et al. (1984), conforme o nivel de inundação que suportam: flutuantes fixas (FF), flutuantes livres (FL), submersas fixas (SF), submersas livres (SL), anfibias (AF) e epífitas (EP).

O monitoramento de macrófitas no reservatório de abastecimento de água ou de usinas hidroelétricas tem sido uma preocupação na última década. Na represa Alagados isso se faz necessário, uma vez que resíduos urbanos industriais e residenciais, bem como dejetos de áreas rurais, são descartados direta ou indiretamente nesse ambiente. Essas interferências antrópicas sem planejamento e controle favorecem a eutrofização do lago e o desequilibrio do ambiente, provocando o desenvolvimento populacional de determinadas espécies em detrimento de outras, como observado por Domingos (2011). O monitoramento pode dar suporte para medidas de prevenção do aumento do volume de plantas no reservatório, que compromete a qualidade ambiental e a qualidade de serviços prestados a comunidade.

O objetivo deste trabalho foi realizar o inventário de plantas aquáticas ocorrentes na represa Alagados, em Ponta Grossa-PR, como medida de monitoramento da área, bem como indicar as principais espécies e sua frequência e realizar um diagnóstico sobre o avanço populacional destas.

\section{MATERIAL E MÉTODOS}

A represa Alagados é um reservatório artificial de água localizado próximo aos municípios de Ponta Grossa, Castro e Carambeí, no Estado do Paraná-Brasil, numa microbacia que abrange os rios Pitangui e Jotuba, principalmente. Esse reservatório abastece, em parte, a população do município de Ponta Grossa, além de ser utilizado para gerar energia elétrica (Figura 1A). Na margem direita, próximo à barragem e à estação de captação de água, está instalado o Iate Club de Ponta Grossa.

Para realizar esse inventário, foram programadas 10 coletas em 48 pontos de amostragem ao longo das margens do lago da represa, conforme mostrado na Figura 1B. A represa apresenta extensão aproximada de $15 \mathrm{~km}$, largura média de $500 \mathrm{~m}$ e profundidade de $15 \mathrm{~m}$ na região próxima à barragem, com variações de 2 a $5 \mathrm{~m}$ no restante da área. Uma particularidade nessa represa é a presença de grandes troncos de árvores mortas, que permanecem na área e comprometem a navegação durante os períodos de seca, quando o nivel da água torna-se mais baixo. As coletas ocorreram no período de agosto de 2007 a julho de 2008; não foi possível a navegação nos meses de setembro de 2007 e janeiro de 2008.

As coletas foram feitas com o auxílio de barco a motor, cedido pela SANEPAR, que mantém um convênio com a UEPG através do NUCLEAM para realização de estudos nesse local. Os exemplares amostrados continham ramos reprodutivos, com exceção de plantas que não produzem flores, as pteridófitas, para a montagem de exsicatas, as quais foram depositadas no Herbário da Universidade Estadual de Ponta Grossa (HUPG), inserido no Index Herbariorum e no programa Taxon-line, uma rede paranaense de coleções científicas, o que o torna uma importante fonte de pesquisa e ensino sobre o conhecimento da flora paranaense.

As identificações foram feitas com base em comparações com exsicatas já depositadas nesse herbário, bem como com outras depositadas no Herbário do Museu Botânico Municipal (MBM), em Curitiba, e também com material de literatura especializada da área.

A terminologia para classificar as plantas por categorias, de acordo com as formas de vida, foi feita com base em Irgang et al. (1984). Para a análise fitossociológica, foram utilizados parâmetros descritos por MüellerDombois \& Ellenberg (1974). 




(A)

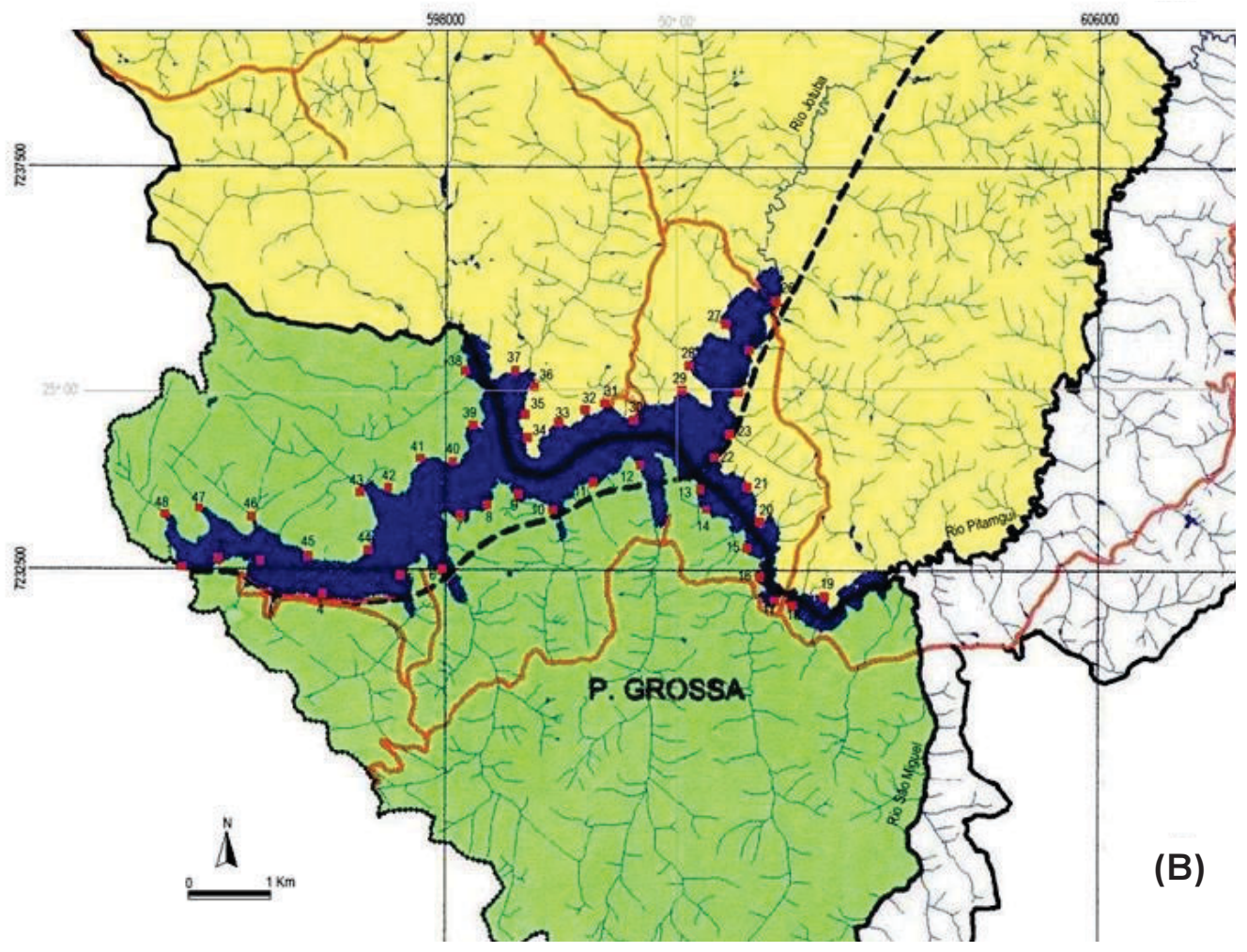

Figura 1 - Localização da represa Alagados, Ponta Grossa, Paraná-Brasil (A) e indicação dos pontos de amostragem de plantas aquáticas (B) - agosto de 2007/julho de 2008.

\section{RESULTADOS E DISCUSSÃO}

Um diagnóstico preliminar das condições ambientais no entorno da bacia Alagados foi elaborado pelo Núcleo de Estudos Ambientais da Universidade Estadual de Ponta Grossa (NUCLEAM-UEPG); a partir deste estudo, foi elaborado o programa de recuperação ambiental da Bacia Hidrográfica do Manancial Alagados, envolvendo parceiros como a Companhia de Saneamento Básico do Estado do Paraná (SANEPAR), a Companhia de Eletricidade (COPEL) e o Instituto Ambiental do Paraná (IAP) (Pilatti, 2002, 2003). O presente 
trabalho foi inserido nesse programa, como um dos 17 projetos que foram desenvolvidos em 2007 / 2008 junto ao NUCLEAM-UEPG.

A Tabela 1 apresenta a relação de plantas amostradas no entorno da represa. Foram amostradas 54 espécies, distribuídas em 16 famílias de angiospermas, 8 monocotiledôneas e 8 dicotiledôneas, e outras duas famílias de pteridófitas. Do total de exemplares amostrados, somente três Poaceae e uma Cyperaceae foram identificadas apenas em nível de família.

Esses dados apresentam divergências quantitativa e qualitativamente, em comparação com os apresentados num inventário preliminar realizado por Moro et al. (2009) na represa Alagados, que relataram 22 famílias, 30 gêneros e 42 espécies, sem no entanto apresentar a listagem de espécies ou a frequência destas. Também nessa obra não há esclarecimento quanto ao número de coletas ou ao número de pontos de amostragem realizados para resultar nesses valores.
Comparativamente, exemplares de 10 familias relatadas por esses autores não foram amostrados nesse relatório; entretanto, seis outras aqui amostradas não constam da relação desses autores. Ressalta-se que a maior divergência entre essas listagens encontra-se no número de representantes das famílias Poaceae e Asteraceae, indicando perda da biodiversidade e antropização do ambiente.

A estação de captação de água da SANEPAR (Figura 2A) foi estabelecida como o ponto $1 \mathrm{de}$ coleta (Figura 1B). Na margem direita em relação à estação da SANEPAR, nenhuma planta foi amostrada nos pontos 2, 3, 4 e 5 (Figura 1B), onde se localiza o Iate Clube de Ponta Grossa (Figura 2B). Às margens da represa também são observadas propriedades rurais com atividades agropecuárias (Figura $2 \mathrm{C}$ ). Em alguns pontos, observa-se o desequilibrio do ambiente (Figura 2D-F).

No entanto, a numerosa quantidade de famílias, gêneros e espécies identificados no entorno da represa (Tabela 1) mostrou que o
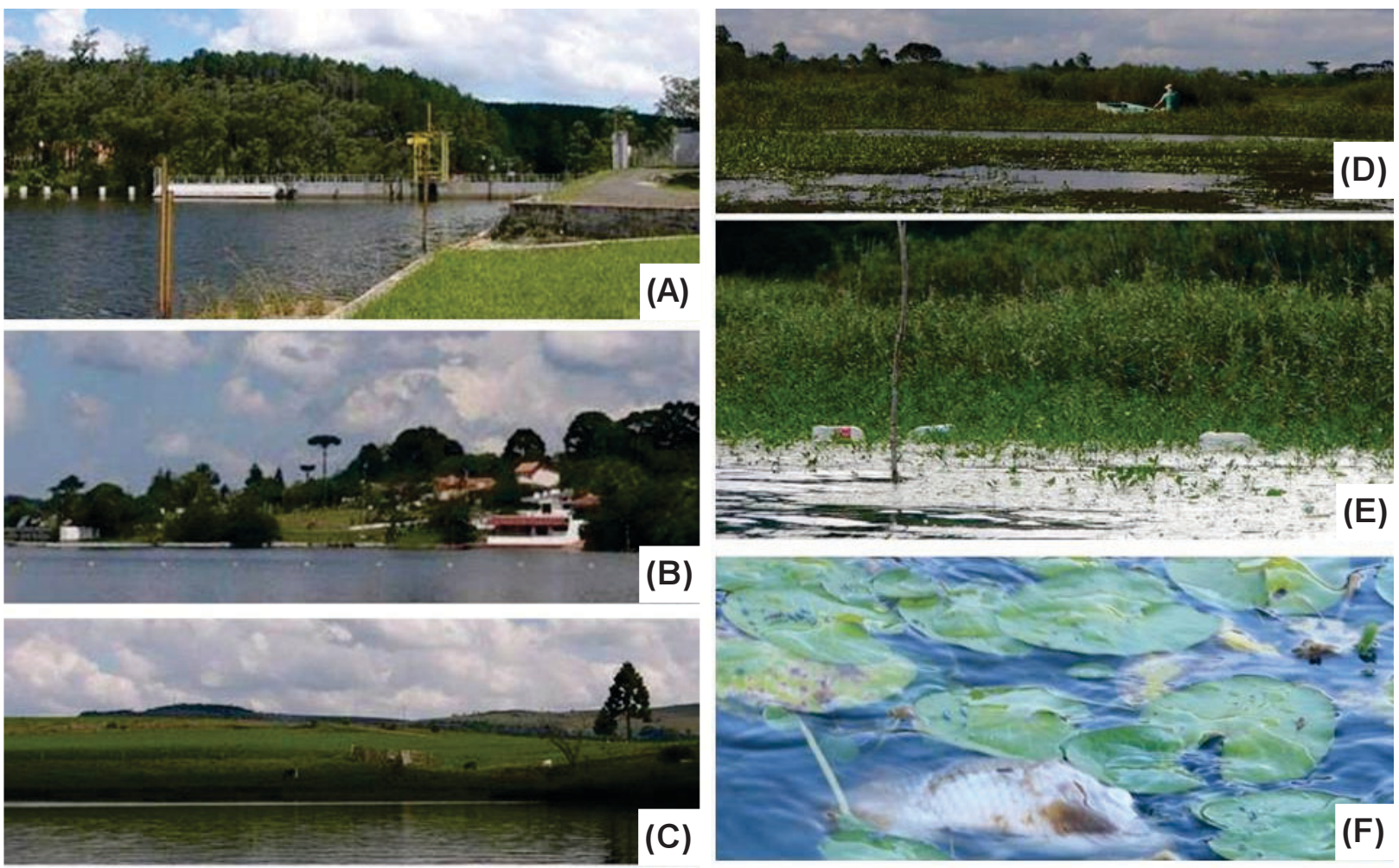

Figura 2 - Áreas antropizadas às margens da represa Alagados, Ponta Grossa-PR, e os efeitos sobre o ambiente. (A) barragem e estação da SANEPAR. (B) vista geral do Iate Clube de Ponta Grossa; (C) propriedade rural com atividades agropecuárias; (D-F). efeitos do desequilíbrio ambiental. 
Tabela 1 - Relação de espécies amostradas na represa Alagados, Ponta Grossa-PR, no período de agosto de 2007 a julho de 2008

\begin{tabular}{|c|c|c|c|}
\hline Família & Nome científico & Categoria & $\mathrm{F}$ \\
\hline \multirow{9}{*}{ ASTERACEAE } & Ageratum conyzoides L. & $A F$ & 0,02 \\
\hline & Bracharidastrum triplenervium (Less.) Cabrera & $A F$ & 0,02 \\
\hline & Bacharis sp. & $A F$ & 0,06 \\
\hline & Campuloclinium purpurascens (Sch. Bip.) R.M. King \& H.Rob. & $A F$ & 0,06 \\
\hline & Gamochaeta filiginea (D.C.) Cabrera & $A F$ & 0,02 \\
\hline & Gamochaeta pensilvanica (Willd.) Cabrera & $A F$ & 0,02 \\
\hline & Mikania micrantha Kunth. & $E P$ & 0,06 \\
\hline & \begin{tabular}{|l} 
Sonchus oleraceus L. \\
\end{tabular} & $A F$ & 0,04 \\
\hline & Senecio brasiliensis (Spreng.) Less. & $A F$ & 0,04 \\
\hline ALISMATACEAE & Echinodorus grandiflorum Mitch. & $A F$ & 0,04 \\
\hline AMARANTHACEAE & Alternanthera philoxeroides (Mart.) Griseb. Abdh Ges. Wiss. Coett. & $A F$ & 0,02 \\
\hline COMMELINACEAE & Commelina diffusa Burm $\mathrm{f}$. & $A F$ & 0,15 \\
\hline \multirow{10}{*}{ CYPERACEAE } & Cyperus densicapitosus Mattf. et Kubenth & $A F$ & 0,04 \\
\hline & Cyperus esculentus L. & $A F$ & 0,02 \\
\hline & Cyperus giganteus Vahl & $A F$ & 0,52 \\
\hline & Cyperus luzulae (L.) Retz. & $A F$ & 0,02 \\
\hline & Cyperus rigens J. Presl. \& C. Presl. subesp. rigens var. rigens & $A F$ & 0,02 \\
\hline & Cyperus virens Michx. & $A F$ & 0,04 \\
\hline & Fimbristilis squarrosa Vahl & $S F$ & 0,02 \\
\hline & Eleocharis $\mathrm{sp}$. & $S F$ & 0,06 \\
\hline & Rhynchospora corymbosa var. aspérula (Nees) Kük. & $A F$ & 0,06 \\
\hline & Sp. 1 & $S F$ & 0,02 \\
\hline IRIDACEAE & Sisyrichium commutatum Klatt & $A F$ & 0,02 \\
\hline \multirow{2}{*}{ JUNCACEAE } & Juncus tenuis Willd var. dichotomus (Elliot) Wood & $A F$ & 0,02 \\
\hline & Juncus microcephalus Kunth. & $A F$ & 0,04 \\
\hline LYTHRACEAE & Cuphea carthagenensis (Jacq.) Macbride & $A F$ & 0,10 \\
\hline MENYANTACEAE & Nymphoides indica (L.) O. Kuntze & $F F$ & 0,58 \\
\hline \multirow{2}{*}{ ONAGRACEAE } & Ludwigia sp. (Cambess.) H. Hara & $E M$ & 0,46 \\
\hline & Ludwigia sericea (Cambess.) H. Hara & $A F$ & 0,08 \\
\hline \multirow{11}{*}{ POACEAE } & Andropogon sp. & $A F$ & 0,06 \\
\hline & Aristida sp. & $A F$ & 0,06 \\
\hline & Echinochloa sp. & $A F$ & 0,02 \\
\hline & Panicum aquaticum Poir & $E M$ & 0,13 \\
\hline & Panicum aristelium Döll. & $A F$ & 0,06 \\
\hline & Panicum glabripes Döll & $E M$ & 0,10 \\
\hline & Penisetum sp. & $A F$ & 0,10 \\
\hline & Setaria $\mathrm{sp}$. & $A F$ & 0,02 \\
\hline & sp. 1 & $A F$ & 0,02 \\
\hline & sp. 2 & $A F$ & 0,02 \\
\hline & sp. 3 & $A F$ & 0,02 \\
\hline \multirow{5}{*}{ POLYGONACEAE. } & Polygonum acumintatum Kunth. & $E M$ & 0,46 \\
\hline & Polygonum hidropeperoides Michx. & $E M$ & 0,40 \\
\hline & Polygonum persicaria $\mathrm{L}$. & $E M$ & 0,10 \\
\hline & Polygonum rubricaule Benth. & $E M$ & 0,29 \\
\hline & Polygonum stelligerum Cham. & $E M$ & 0,23 \\
\hline \multirow{3}{*}{ PONTEDERIACEAE } & Echnodorus sp. & $E M$ & 0,02 \\
\hline & Eichhornia crassipes (Mart.) Solms & $F L$ & 0,04 \\
\hline & Pontederia cordata $\mathrm{L}$. & $A F$ & 0,25 \\
\hline RANUNCULACEAE & Ranunculus bonariensis Poir & $A F$ & 0,02 \\
\hline \multirow[t]{2}{*}{ SCROPHULARIACEAE } & $\begin{array}{l}\text { Mercadonia tenella (Cham. et Schlecht.) Pennel var. microphyla (Schmidt) } \\
\text { Rossow }\end{array}$ & $A F$ & 0,02 \\
\hline & Bacopa sp. & $A F$ & 0,02 \\
\hline THYPHACEAE & Typha dominguensis Pers. & $A F$ & 0,02 \\
\hline \multirow[t]{2}{*}{ SALVINACEAE } & Salvinia sp.1 & $F L$ & 0,35 \\
\hline & Salvinia sp. 2 & $F L$ & 0,04 \\
\hline AZOLLACEAE & Azzolla sp. & $F L$ & 0,02 \\
\hline
\end{tabular}

$\mathrm{C}=$ categorias. $A F=$ anfíbia. $E M=$ emergente. $E P=$ epífita. $F F=$ flutuante fixa. $F L=$ flutuante livre. $f=$ frequência absoluta (número de amostras/total de pontos). 
ambiente ainda preserva considerável diversidade biológica, e o monitoramento dessa diversidade é essencial para que o desequilíbrio seja minimizado.

Esse inventário registrou as maiores frequências (entre 0,58 e 0,46) para Nymphoides indica (Menyantaceae), Cyperus giganteus (Cyperaceae), Ludwigia sp. e Polygonum acumintatum (Polygonaceae) (Tabela 1 e Figura 3). Os elevados valores devem ser observados com cautela, pois refletem colonização e/ou crescimento populacional acelerado dessas plantas.

A ocupação estratificada de macrófitas, conforme salientaram Irgang et al. (1984) e Scremin-Dias (2000), foi observada. Geralmente, as áreas mais distantes do filme d'água são ocupadas por grandes populações de Cyperus giganteus (Figura 3I), enquanto espécies de poligonáceas e grandes populações de Ludwigia sp. (Figura 3F) habitam o ambiente mais próximo ao filme d'água, em solo inundado a maior parte do ano. Nymphoides indica (Figura 3B) coloniza grandes áreas permanentemente inundadas (Figura 4).

Essa zonação ecológica reflete os diferentes graus de adaptação de que essas espécies necessitam para tolerar o estresse do dessecamento ao qual ficam submetidas durante o período de seca, entre julho e outubro, quando os niveis de água do reservatório diminuem, formando uma faixa de praia às margens do lago. As plantas anfibias (AF), que ocupam os pontos mais distantes do lago, devem ser as que mais toleram o dessecamento, pois somente em períodos curtos durante o ano permanecem com o corpo vegetativo parcialmente inundado. As plantas emergentes (EM) são mais suscetiveis ao dessecamento que as anfíbias e mais tolerantes que as espécies flutuantes livres (FL) ou fixas $(\mathrm{FF})$ e as submersas fixas ou livres (SF e SL). Provavelmente, os diferentes graus de tolerância ao dessecamento dessas macrófitas contribuem para o sucesso e o estabelecimento delas em relação a outras, favorecendo o aumento populacional nesse ambiente.

A ciperácea $C$. giganteus é uma planta anfíbia, enquanto as poligonáceas e onagráceas podem ser classificadas como plantas emergentes, conforme a proposta de Irgang et al. (1984) e em conformidade com Pott \& Pott (2000). No entanto, Ridge (1987) considera que as plantas emergentes também podem ser classificadas como plantas anfíbias, uma vez que a definição indica serem plantas que se reproduzem sexuadamente no ambiente aquático, onde passam a maior parte do seu ciclo de vida, tolerando os períodos de dessecamento e sobrevivendo nesse ambiente aéreo. No presente trabalho, após observações in loco, optou-se por manter a terminologia de Irgang et al. (1984). Contudo, foi observado que tanto as poligonáceas como Ludwigia sp. só iniciaram a floração após o aumento do nivel das águas no reservatório.

Essas macrófitas emergentes são muito frequentes no ambiente e se beneficiam com o assoreamento e a eutrofização do lago para reproduzir-se e dispersar-se, aumentando a biomassa submersa, pois parte de seu corpo vegetativo permanece sob o filme de água, elevando a sua turbidez, além de causar dificuldades de navegação.

É relevante, portanto, o fato de não terem sido amostradas plantas submersas livres. Segundo Bini \& Thomaz (2005) e Carvalho et al. (2005), quanto maiores os valores de turbidez da água, menor a colonização por plantas submersas. Além disso, segundo Thomaz (2006), as espécies submersas preferem ambientes oligomesotróficos.

Por outro lado, três espécies flutuantes estão também entre as mais frequentes na área em estudo. Nymphoides indica é uma planta flutuante fixa, e as duas espécies de salvínia são flutuantes livres, cujo aumento populacional também pode interferir na captação de luz por parte das plantas submersas ou emergentes, pela ocupação total da superficie da água, interferindo na navegação e na oxigenação da água e provocando prejuízos ambientais (Figura 2F). Um fator agravante da presença dessas espécies flutuantes é a elevada capacidade de deslocamento que elas têm num ambiente lótico, o que pode comprometer o uso de equipamentos para geração de energia e tubulações para captação de água, elevando assim os custos da manutenção de produção e serviços. A espécie $N$. indica é fixa no substrato, porém em determinada época do 


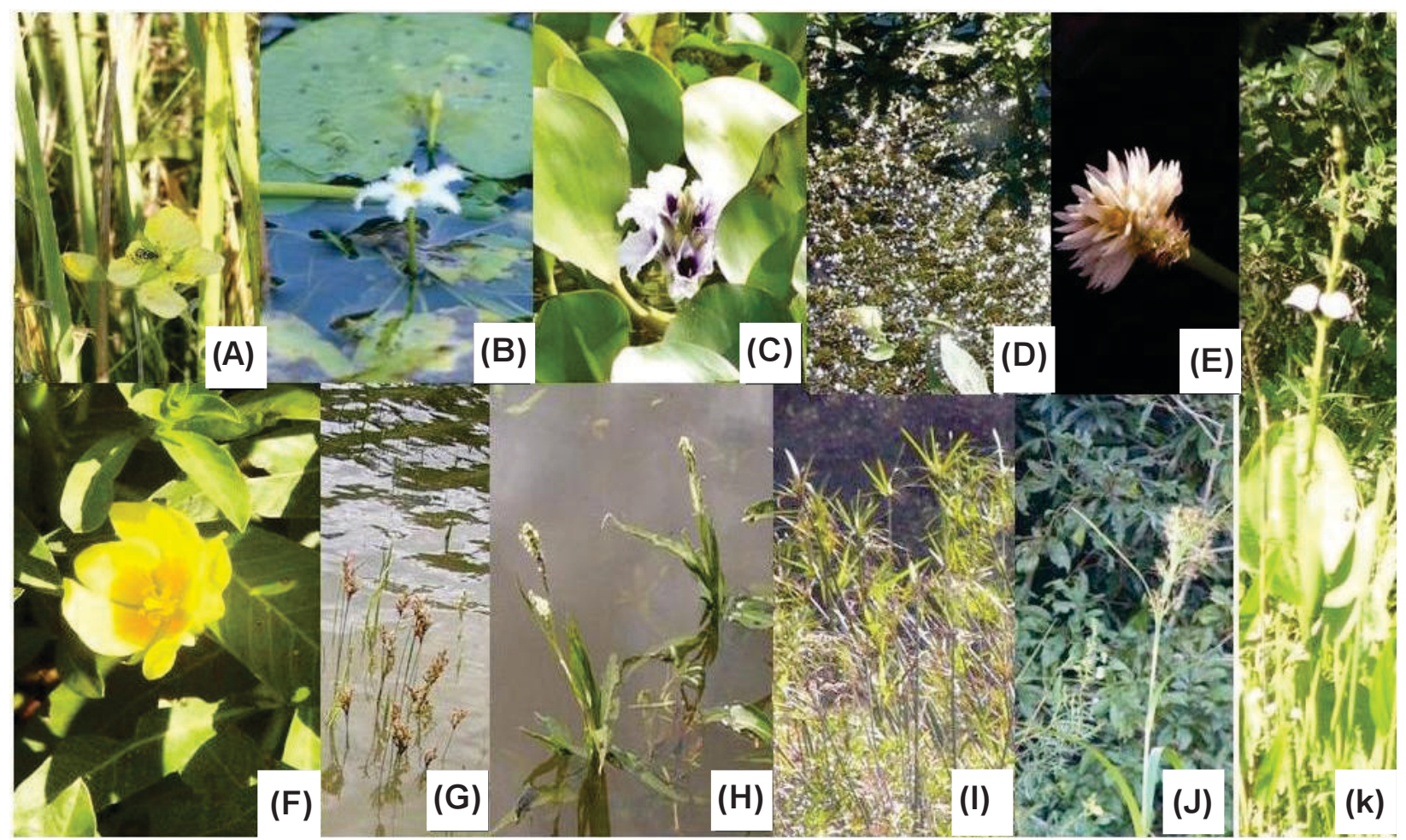

Figura 3 - Diversidade de espécies vegetais amostradas na represa Alagados, Ponta Grossa-PR, no período de agosto de 2007 a julho de 2008. (A)Ludwiguia sericea. (Onagraceae); (B) Nymphoides indica (Menyantaceae); (C)Eichhornia crassipes (Pontederiaceae); (D) Salvinia spp. (Salvinaceae); (E) Alternanthera philoxeroides (Amaranthaceae); (F) Ludwiguia sp. (Onagraceae); (G) Juncus microcephalus (Juncaceae); (H) Polygonum acuminatum (Polygonaceae); (I) Cyperus giganteus (Cyperaceae); (J) Rhynchospora corymbosa (Cyperaceae); (K) Echnodorus sp. (Pontederiaceae).

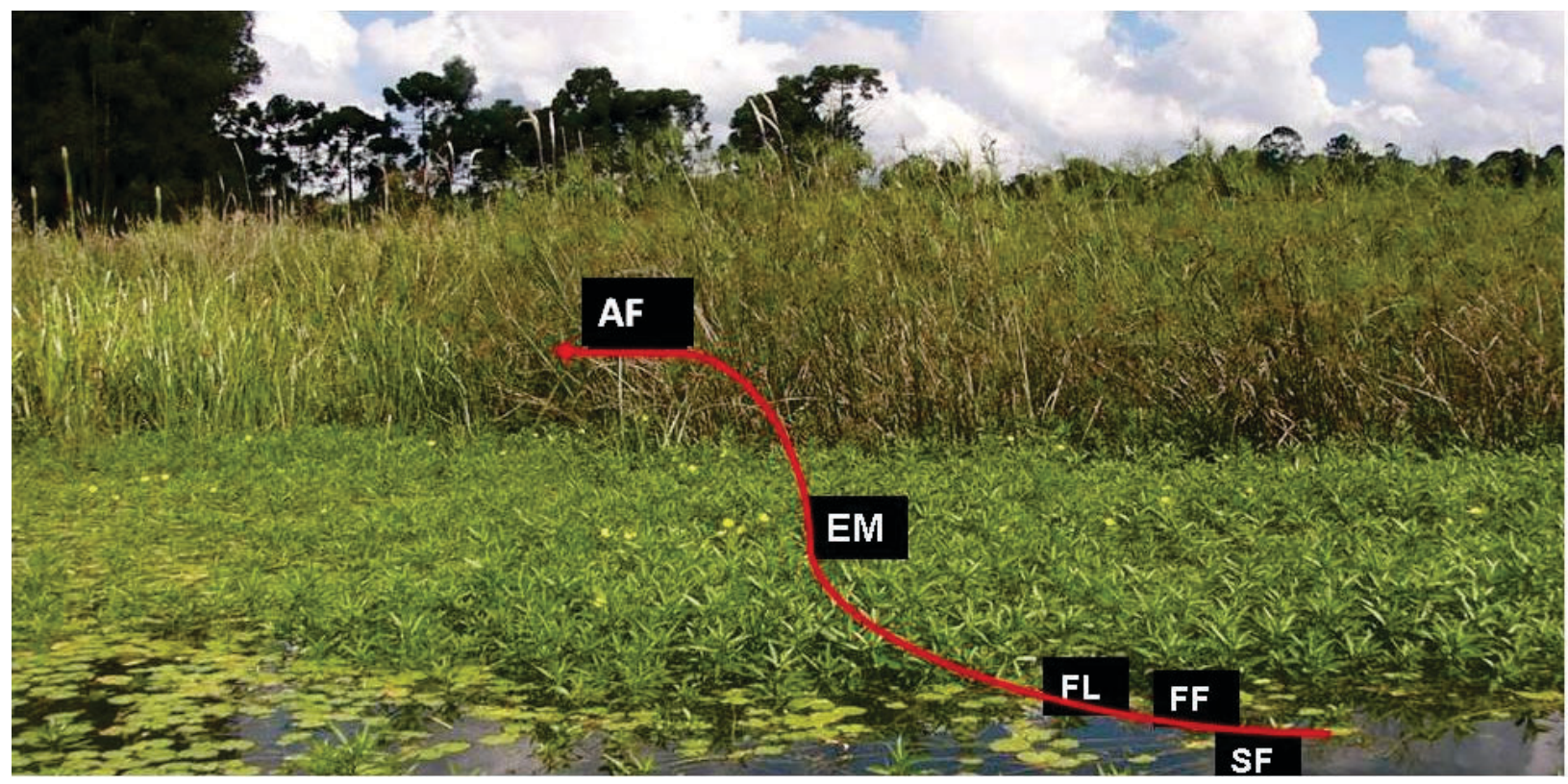

Figura 4 - Estratificação das macrófitas na represa Alagados, Ponta Grossa-PR. A linha vermelha indica o nível da água em diferentes períodos ao longo do ano. $\mathrm{AF}=$ anfíbias (ou palustres); $\mathrm{EM}=$ emergentes; $\mathrm{FF}=$ flutuantes fixas; $\mathrm{FL}=$ flutuantes livres; $\mathrm{SF}=$ submersas fixas. 
ano, ao reproduzir-se, solta fragmentos do corpo vegetativo e se dispersa no lago. Esse período coincide com a cheia.

Macrófitas flutuantes livres que infestam reservatórios de hidrelétricas e atingem as turbinas geradoras de energia podem causar quebra e paralisação de equipamentos (Martins et al., 2003). Registrou-se pequena ocorrência de aguapé, Eichhornia crassipes (Figura 3C), considerada a principal planta daninha do tipo flutuante livre no mundo. Isso pode ser justificado pelas temperaturas baixas que atingem a região, localizada em latitude superior a $40^{\circ}$ (Thomaz, 2006).

A presença de plantas flutuantes livres está relacionada à maior disponibilidade de fósforo e nitrogênio na água - nutrientes limitantes para o desenvolvimento de espécies com essa forma de vida (Thomaz, 2006). Na represa Alagados, esses componentes podem estar disponiveis por decomposição da matéria orgânica ou por carreamento de adubos agrícolas.

A presença de espécies de Asteraceae e de Poaceae (Tabela 1) pode ser interpretada como mais um fator indicativo de ambiente antropizado.

As grandes populações de macrófitas foram observadas na margem direita da represa, tomando como referência a estação da SANEPAR. Essa ocupação mais intensa na margem direita (Figuras 1B e 2A) pode estar relacionada à direção dos ventos, predominante na região de nordeste para sudoeste (Cruz, 2007).

As três maiores colonizações de macrófitas foram registradas nas regiões de entradas dos rios que constituem a microbacia: Pitangui (pontos 18 e 19), rio Jotuba (pontos 25, 26 e 27) e Moquém (Figura 1). Nessas três áreas, a navegação já está parcialmente comprometida. Resíduos agrícolas, como fertilizantes, e os resíduos provenientes de atividades agropecuárias, como dejetos de animais que são carreados pelos rios, possivelmente estão favorecendo o desequilíbrio populacional. DOMINGOS, et al. (2011) comentam que rios e lagos tem sofrido eutrofização devido ao aporte de nutrientes provenientes de dejetos industriais ou agrícolas promovendo produtividade biológica, afetando a vegetação aquática.Segundo Thomaz (2006), fatores abióticos também podem ser responsáveis pelo estabelecimento das macrófitas em determinados pontos de lagos e represas, rios e açudes, entre eles a baixa velocidade da água e o assoreamento das margens.

Investigações futuras poderão ser realizadas para verificar quais e quantos desses fatores devem estar interferindo e favorecendo a explosão populacional observada para determinadas macrófitas nessas três áreas indicadas com maior grau de infestação, visto que já está em andamento um programa de recuperação da Bacia Hidrográfica do Manancial Alagados (Pilatti, 2003).
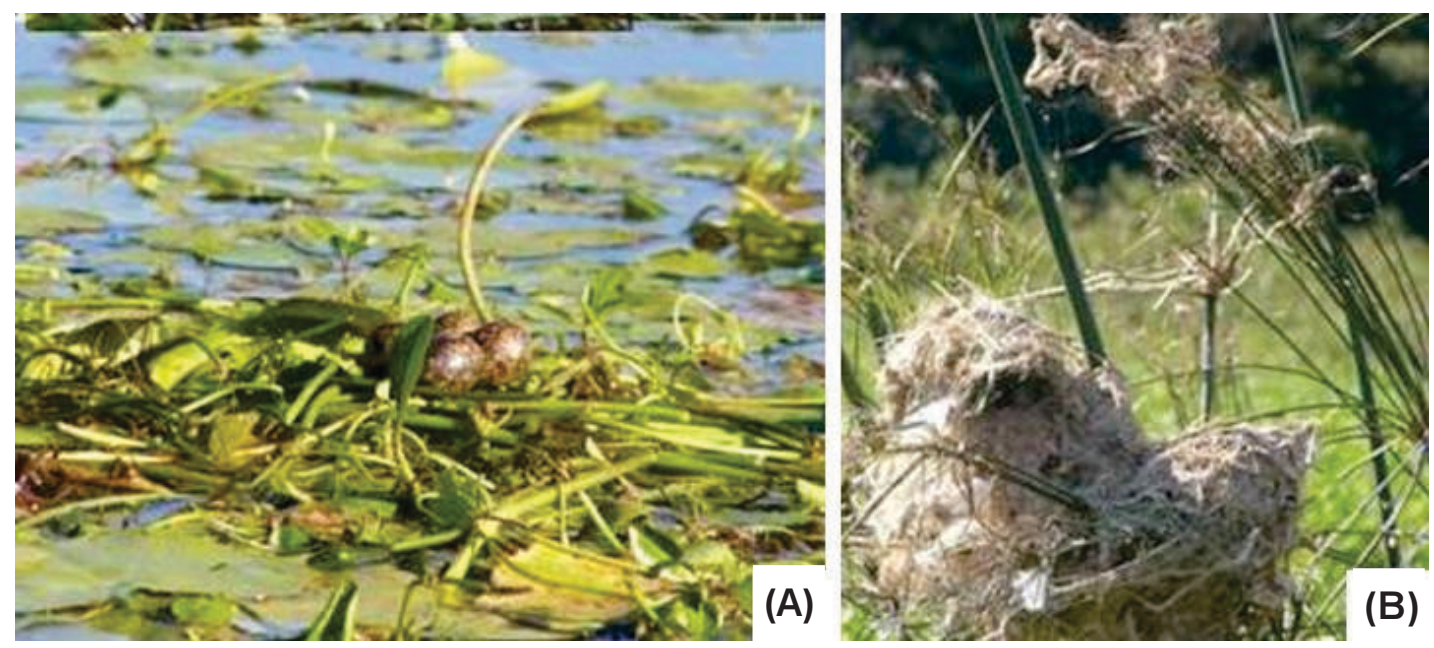

Figura 5 - Ninhos de pássaros na represa Alagados, Ponta Grosa-PR. (A) construído sobre o filme d'água com Nymphoides indica; (B) construído no entorno do lago, sobre escapos de Cyperus giganteus. 
A importância das macrófitas foi verificada in loco nesse ambiente, como abrigo e ambiente de reprodução de alguns pássaros (Figura 5), indicando como a fauna se comporta nesse reservatório; esse conhecimento poderá auxiliar na tomada de decisões futuras.

Os dados de diversidade biológica e de frequência das espécies vegetais que ocupam a área da represa Alagados, bem como o mapeamento das maiores colonizações nas três entradas de rios, podem servir de apoio para atitudes que visem à conservação e preservação do ambiente, a fim de melhorar a qualidade da água oferecida à sociedade.

Prioritariamente, existe a necessidade de monitoramento das principais espécies colonizadoras, particularmente das flutuantes, para conter a dispersão e evitar futuros problemas por danos aos equipamentos de geração de energia. Em médio prazo, será necessário investigar e minimizar as causas que favoreceram a grande colonização de macrófitas nas três entradas de rios.

\section{AGRADECIMENTOS}

Ao CNPq, pela bolsa concedida. À SANEPAR, pelo apoio logístico, em especial ao sr. Carlos Daniel Mendes, que auxiliou diretamente nas coletas.

\section{LITERATURA CITADA}

BINI, L. M.; THOMAZ, S. M. Prediction of Egeria najas and Egeria densa occurrence in a large subtropical reservoir (Itaipu Reservoir, Brazil-Paraguay). Aquat. Bot., v. 83, n. 1, p. $15-22,2005$.

CARVALHO, F. T. et al. Plantas aquáticas e nível de infestação das espécies presentes no reservatório de Barra Bonita, no rio Tietê. Planta Daninha, v. 21, p. 15-20, 2003. (Edição Especial)

CARVALHO, F. T. et al. Influência da turbidez da água do rio Tietê na ocorrência de plantas aquáticas. Planta Daninha, v. 23 , n. 2 , p. $359-362,2005$

CRUZ, G. C. F. Alguns aspectos do clima dos Campos Gerais. In: MELO, M. S.; MORO, R.S.; GUIMARÃES, G. B. Patrimônio natural dos Campos Gerais do Paraná. Ponta Grossa: UEPG, 2007. p. 59-72.
DOMINGOS, et al. .Fatores ambientais na distribuição de populações de Brachiaria subquadripara presentes no Reservatório de Barra Bonita-SP. Planta Daninha [online], v.29, n.1.2011. Disponível em: <http://www.scielo.br/ scielo.php? script $=$ sci_arttext\&pid $=\mathrm{S} 0100$ -

$83582011000100005 \& \operatorname{lng}=$ pt\&nrm=iso $>$. Acesso em: 4 maio 2011.

IRGANG B. E.; PEDRALLI, G.; WAECHTER, J. L. Macrófitos aquáticos da estação Ecologia do Taim, Rio Grande do Sul, Brasil. Rosseleria, v. 6, n. 3, p. 395-404, 1984.

MARTINS, D. et al. Caracterização química das plantas aquáticas coletadas no reservatório de Salto Grande (Americana-SP). Planta Daninha, v. 21, p. 21-26, 2003 (Edição Especial)

MARTINS, D. et al. Caracterização da comunidade de plantas aquáticas de dezoito reservatórios pertencentes a cinco bacias hidrográficas do Estado de São Paulo. Planta Daninha, v. 26, n. 1, p. 17-32, 2008

MARTINS, D. et al. Levantamento da infestação de plantas aquáticas em Porto Primavera antes do enchimento final do reservatório. Planta Daninha, v. 27, p. 879-886, 2009.

(Edição Especial)

MARTINS, D. et al . Levantamento de plantas aquáticas no reservatório de Salto Grande, Americana-SP. Planta Daninha [on line], v.29, n.1,2011. Disponível em: http:// www.scielo.br/scielo.php?script=sci_arttext\&pid= S010083582011000100025\&lng=pt\&nrm=iso. Acesso em: 4 maio 2011 .

MELO, M. S.; MORO, R. S.; GUIMARÃES, G. B. Patrimônio natural dos Campos Gerais do Paraná. Ponta Grossa: UEPG, 2007. 203 p.

MORO, R. S.; CARMO, M. R. B. A vegetação campestre dos Campos Gerais. In: MELO, M. S.; MORO, R. S.; GUIMARÃES, G. B. Patrimônio natural dos Campos Gerais do Paraná. Ponta Grossa: UEPG, 2007. p. 93-98.

PILATTI, F. (Coord.). Bacia hidrográfica do manancial Alagados. Ponta Grossa: UEPG/COPEL/SANEPAR/ALL/ IAP, 2002. 82 p. (Relatório Técnico)

PILATTI, F. (Coord.). Programa de recuperação da Bacia hidrográfica do manancial Alagados. Ponta Grossa: UEPG/ COPEL/SANEPAR/ALL/IAP, 2003. 96 p.

POTT, V. J.; POTT, A. Plantas aquáticas do Pantanal Brasília: Embrapa, 2000. 404 p.

RIDGE, I. Ethylene and growth control in amphibious plants In: CRAWFORD, R. M. M. Plant life in aquatic and amphibious habitats. Oxford: Blackwell Scientific Publications, 1987. p. 53-76. 
SCREMI-DIAS, E. A plasticidade fenotípica das macrófitas aquáticas em resposta à dinâmica ambiental. In: CAVALCANTI, T. B. et al. (Orgs.) Tópicos atuais em botânica. Brasília: Embrapa Recursos Genéticos e Biotecnologia-SBB, 2000. p. 187-194.
THOMAZ, S. M. Efeitos de fatores limnológicos sobre a colonização e estrutura de assembléias de macrófitas aquáticas. In: MARIATH, J. E. A.; SANTOS, R. P. (Org.). Os avanços da botânica no início do século XXI: morfologia, fisiologia, taxonomia, ecologia e genética. Porto Alegre: Sociedade Botânica do Brasil, 2006. p. 124-139 